\title{
Thermodynamic sustainability assessment for heating of residential building
}

\author{
Milan Gojak ${ }^{1, *}$ and Tamara Bajc $^{2}$ \\ ${ }^{1}$ Faculty of Mechanical Engineering University of Belgrade, Thermo-mechanics Department, 11120 Kraljice Marije, Belgrade, Serbia \\ ${ }^{2}$ Faculty of Mechanical Engineering University of Belgrade, Thermal Science Engineering Department, 11120 Kraljice Marije, \\ Belgrade, Serbia
}

\begin{abstract}
More than one third of the world's primary energy demand refers to residential sector. Heating is considered as one of the main part of the energy consumption in buildings. In this study, a thermodynamic sustainability assessment analysis of different energy sources for heating of residential building, with net floor heated area of $162 \mathrm{~m}^{2}$, for Belgrade weather data, was presented. Five options of energy sources were studied, namely: coal, natural gas, electricity, district heating and air-water heat pump. Energy and exergy analyses were conducted and appropriate efficiencies were determined. Energy and exergy flows in boundaries of the building and in the whole chain from primary to final values were analyzed. The environmental impact factor and exergetic sustainability index were determined for all considered energy sources. The exergy efficiency is very low in all analyzed cases, which further implies poor thermodynamic compatibility of energy quality from the supplied side and the energy used for building heating. It was shown that the highest exergy efficiency is for the case of heat pump utilization (about 6\%), due to the energy used from environment. The minimum environmental impact factor (15.37) and maximum exergetic sustainability index (0.065) were found for the case of heat pump utilization.
\end{abstract}

\section{Introduction}

Residential sector is a large consumer of energy, with a share more than $40 \%$, according to the European Commission data [1]. Heating systems are considered as one of the main part of the energy consumers in buildings. Therefore, energy utilization for thermodynamically efficient and environmentally friendly heating is very important for the development of the sustainable energy systems. In buildings, a large part of the total energy is used as a low quality heat at relatively low temperatures. The largest part of this energy is produced from high quality primary energy sources, such as natural gas, coal, oil, etc. The energy analysis is not capable to illustrate this discrepancy between the quality of the energy on the supply side and on the side of use. Exergy analysis clearly shows this mismatch as a thermodynamic discrepancy.

The valorisation of quality of the source is not possible without exergetic analyzes which should be observed for the whole chain of energy flow. By using exergy efficiencies, it is possible to locate the part of energy chain with the highest losses. At this stage of analysis it is very important whether the exergy efficiencies are calculated on average bases or on the monthly based reference conditions of environment. Torio et al. [2] demonstrated on the example the variations in results if the defined environment reference values are steady-state or dynamic. This is especially visible in case of exergy analyse of heating and cooling systems. Various authors used dynamic exergy approach [3-7], having in mind the sensitivity of chosen reference values.

Martinaitis et al. [8] suggested an application of degree-days for exergy analysis for buildings. They proposed the equation for duration of exergy demand analogical to degree-days for heating, together with the non-dimensional energy climatic indicators. Yildiz and Gungor [9] analyzed energy and exergy flows for heating of building in Izmir using steady-state approach. The results showed that the biggest losses in energy and exergy chains occur after the power plant. In order to overcome this issue and use energy rationally, supply temperatures should be as low as possible [10].

Exergy analysis is a good tool for the long-term and sustainable development. Due to rapid development worldwide, energy efficiency and energy savings strategies has to be observed together with environmental impact. Exergy method of analysis also correlates sustainability and environmental impact, and provides an objective measure of that impact. A fully sustainable process means that there are no exergetic losses, i.e. there is no energy degradation, nor negative impact on environment.

Abu-Rayash and Dincer [11] proposed a new sustainability model for energy system assessment using,

*orresponding author: tbajc@ mas.bg.ac.rs 
which could be used for identification of key parameters for sustainability of systems that use energy. Model includes environmental friendliness index which is a function of a various environmental impacts of a system on a surroundings. In this model, authors suggested the relation for exergy index which scores both exergy efficiency and exergy destruction. Exergy destruction ratio is also considered by Acikkalp et al. [12] who conducted the advanced low exergy analysis for heating systems and concluded that the exergy destruction is the highest at the boiler, while it is the lowest for pipes. Similar as Yucer and Hepbasli [13] who found the biggest exergy losses in generation.

Rosen et al. [14] mentioned two possible approaches to reduce the environmental impact: first is to increase efficiency and the other one is to use the external exergy sources such as renewable energy form environment.

This combination of sustainable and exergy approach is also used in this paper to present the analysis for Serbian case during heating season.

\section{Building and system description}

Serbia has an old building stock with an average energy consumption for heating of $150 \mathrm{kWh} / \mathrm{m}^{2} \mathrm{a}$, which corresponds to consumption for old, non-renovated buildings in European countries [15-17]. The analysis in this paper was done for and new residential building, which has " $\mathrm{C}$ " energy efficiency rating (in accordance with Serbian rulebook on the conditions, content and manner of issuance of certificates of energy performance of building [18]) in order to show how inappropriate choice of energy source can impact the primary energy consumption even though the building has a decent thermal insulation.

For the purpose of the analysis the example residential building with net floor heated area of $162 \mathrm{~m}^{2}$ was used. The building is located in Belgrade, Serbia, which further implies with moderate climate conditions which were used for the analysis. Building thermal envelope was constructed in accordance with $U$-values prescribed by Serbian rulebook on the energy efficiency [19]. Building has the two pipes, radiator central heating system. Five options of energy sources were studied, namely: coal, natural gas, electricity, district heating and air-water heat pump in order to compare the energy and exergy flows and impact of the different energy sources for heating on environment.

\section{Methodology}

\subsection{Energy analysis}

The first step in this analysis was the calculation of energy needs for heating according to the methodology prescribed by actual Serbian rulebook on the energy efficiency [19]. The calculation is performed for final, delivered and primary energy needs for observed building. Annual final energy for heating is calculated according to the standard SRPS EN ISO 52016:2017, where total energy needs for compensation of heat losses is reduced for the amount of energy gained from internal sources and sun, but with a respect to the gain utilization factor as a function of a building type and mass. Energy needs are calculated on monthly bases, for intermittent heating during the night ours.

After the final energy needs, also the delivered energy was calculated with a respect to the energy losses in generation, distribution and automation.

For the conversion to the primary energy, conversion factors from the Serbian rulebook on the energy efficiency [19] were used for each fuel.

Emission of carbon-dioxide is determined based on primary energy for different sources and corresponding specific emissions for each fuel.

\subsection{Exergy analysis}

For better understanding of the nature of energetic processes in systems, in addition to the energy, it is necessary to use the concept of exergy.

In thermodynamics, exergy is usually defined as maximal useful work, which could be obtained by existence of thermodynamic non-equilibrium between the observed system and environment. As the nonequilibrium between the system and environment is bigger, the potential for useful energy is also bigger. In thermodynamically ideal, reversible, processes there is no exergy destruction, while in real processes exergy destruction occurs. Opposite from the energy, in energy processes the exergy can be lost, destroyed, which causes the degradation of energy. Exergy analysis can be useful tool for locating the processes and devices where exergy losses occur and also helps in designing the optimal measures for thermodynamic improvement of process and heating systems.

For exergy analysis the characteristics of a reference environment must be specified. This is commonly done by specifying the temperature, pressure and chemical composition of the reference environment. So, the results of exergy analyses are relative to the specified reference environment. Goncalves et al. showed in reference [20] that the primary exergy ratio depends on the environmental conditions.

Energy flow through the heating chain is calculated in reverse order, from final value, over energy transmitted to the distribution system, then delivered, to primary value, taking into a consideration the corresponding losses in transformation process. In this analysis, the losses were calculated according to the corresponding efficiencies of generation, distribution and automation and also according the primary energy factor for analysed energy sources. For exergy analysis, temperature regimes must be known, so the appropriate temperature regimes were determined in every part of the system. Temperature regimes in emission system and in substation of district heating were determined as a function of outdoor air temperature.

The air temperature in observed building is maintained at a temperature of $20^{\circ} \mathrm{C}\left(T_{i}=293 \mathrm{~K}\right)$ while the average outside air temperature for each month 
during the heating season is $T_{o}$, and values for Belgrade can be found in reference [19]. The exergy demand for maintaining the inside air temperature, $E x_{i}$, is given by equation [21-23]:

$$
E x_{i}=\left(1-\frac{T_{o}}{T_{i}}\right) Q_{h}
$$

where $Q_{h}$ is monthly demand for building heating. The exergy demand of the heating emission system, $\Delta E x_{e}$, can be calculated from:

$$
\Delta E x_{e}=Q_{h}\left(1-\frac{T_{o}}{T_{i n, e}-T_{r e t, e}} \ln \frac{T_{i n, e}}{T_{r e t, e}}\right)
$$

where $T_{i n, e}$ is supply fluid temperature and $T_{\text {ret,e }}$ is return fluid temperature. Heat demand $\left(Q_{d}\right)$ and supply $\left(T_{i n, d}\right)$ and return fluid temperature $\left(T_{r e t, d}\right)$ of the distribution system were calculated by taking into a consideration the efficiencies of distribution and automation system. Expression for exergy demand of the distribution system, $\Delta E x_{d}$, is given as:

$$
\Delta E x_{d}=Q_{d}\left(1-\frac{T_{o}}{T_{i n, d}-T_{r e t, d}} \ln \frac{T_{i n, d}}{T_{r e t, d}}\right)
$$

Exergy demand of the heat generation system, $E x_{g}$, is calculated form:

$$
E x_{g}=F_{q, s} E_{g}
$$

where $F_{q, s}$ is a quality factor of the appropriate energy source (fossil fuel, electricity,...) and $E_{g}$ is energy demand of the heat generation system. Electrical energy could be completely transformed into a different forms of energy, which means that its quality factor is $F_{q, e l}=1$. The exergy of the fuel consists of the thermo-mechanical and chemical exergies. For hydrocarbon fuels specific standard chemical exergy, $e_{x}^{c h}$, can be written as ([13], [24-25]):

$$
e_{x}^{c h}=F_{q, H} H_{H}=F_{q, L} H_{L}
$$

where $F_{q, H}$ and $F_{q, L}$ are corresponding quality factors of the fuel or exergy coefficients, $H_{H}$ is the higher and $H_{L}$ is the lower heating value of the fuel. The specific standard chemical exergy of a fuel usually is considered as approximately equal to higher heating value [24] i.e. the quality factor of the fossil fuels is around 1.

The primary exergy $\left(E x_{p}\right)$ required for the heating is given by:

$$
E x_{p}=F_{q, s} \cdot E_{g} \cdot F_{p, s}+F_{q, e l} \cdot E_{a u x} \cdot F_{p, e l}
$$

where: $E_{\text {aux }}$ is the auxiliary energy (electricity) necessary for heating system operation and $F_{p, s}$ is primary energy factor of the energy source (given in [19]). Index el refers to the electricity.

The exergy efficiency is defined as ratio of useful, final, value and input value, i.e.

$$
\eta_{e x}=\frac{E x_{i}}{E x_{p}}
$$

\subsection{Sustainability and environmental impact analysis}

Sustainable development requires not only usage of sustainable energy resources, but also that these resources must be used efficiently [14]. Exergy analysis is directly linked to sustainability and environmental impact of energetic processes. Hepbasli [26] emphasized the importance of exergy analyses in his study and suggested novel exergy management approach instead of energy. In thermodynamically ideal, reversible, process there is no exergy losses, the exergy efficiency has value 1 , or $100 \%$, and negative impact on the environment does not exist, in other words the process would be completely sustainable. In real processes, which are irreversible, exergy destruction and losses occur. As exergy efficiency approaches value 0 , sustainability approaches zero and environmental impact approaches infinity. Increasing exergy efficiency in utilization contributes to development over a longer period of time, and also decreasing impact on environment. As exergy efficiency approaches $100 \%$, environmental impact approaches zero and sustainability approaches infinity, because exergy is converted from one form to another without losses, and process approaches reversibility.

Exergetic sustainability index $(S I)$ is important objective parameter which enables assessment of the sustainability of energetic process. The relation between exergy efficiency and exergetic sustainability index here is given as:

$$
S I=\frac{\eta_{e x}}{1-\eta_{e x}}
$$

Environmental impact factor $(E I F)$ indicated whether the exergy losses damage the environment. Environmental impact factor is defined as inverse of the exergetic sustainability index:

$$
E I F=\frac{1}{S I}
$$

Low exergetic sustainability index means high environmental impact factor, and vice versa, low environmental impact factor means high exergetic sustainability index.

The methodology of exergetic sustainability indicators calculation can be found also in references [24], [2729]. 


\section{Results}

Energy flow through the system is calculated form final energy needs for heating, than taking into the consideration the corresponding losses in transformation, distribution and automation and conversion to the primary energy. Fig. 1 shows the energy flow diagram through the energy transformation process from primary to final value.

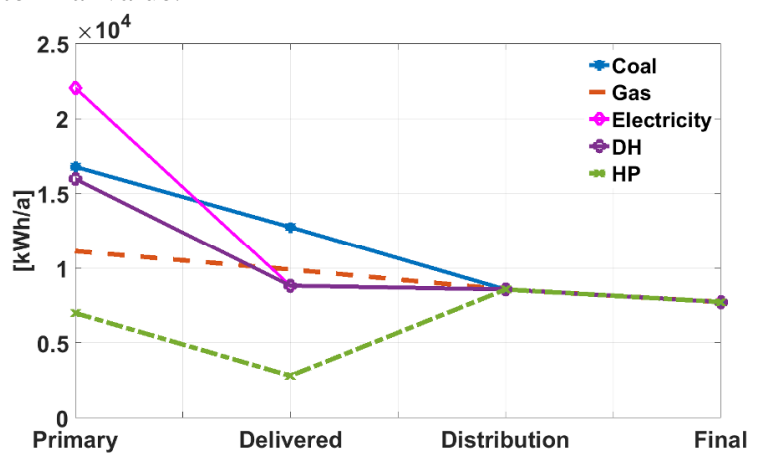

Fig. 1. Energy flow through process of transformation for different energy sources

For different energy sources diagram gives the information regarding the energy efficiency of energy transformation in observed process. Final energy and energy transferred to the distribution system are the same for every considered energy source because the building heating system is the same for all cases. The delivered energy is directly dependent on the efficiency of heat generation system. In the case of coal usage, the heat generation system, boiler, has the lowest efficiency from observed cases and the delivered energy is the highest. The primary energy values are strongly depended on primary energy transformation efficiency, i.e. on primary energy conversion factor for different energy sources. Observing the energy aspects, the electrical energy is the most unfavorable source for heating, because the lowest efficiency during the transformation from primary energy to electricity. For considered district heating system based on fossil fuel (in Belgrade), the primary energy conversion factor has a high value, and thus the difference between the primary and delivered energy is large. For the heat pump the values of primary and delivered energy are the lowest. The difference between energy transferred to the distribution system, and the delivered energy is the energy obtained from the environment.

Corresponding exergy flow for observed building is shown in fig. 2. The flow is presented from primary, delivered and exergy transferred to the distribution system, to the final exergy of indoor air. The primary exergy values are almost equal to the primary energy values (fig.1) because of the high quality of primary energy sources.

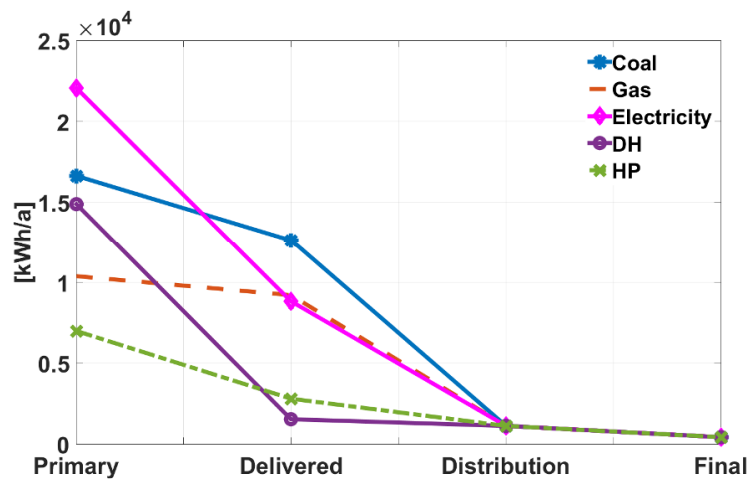

Fig.2. Exergy flow through process of transformation for different energy sources

Delivered exergy for district heating has a significantly lower value than the primary exergy. This is caused by relatively low temperature of hot water delivered to the building substation, which further implies that the delivered exergy is also low. Looking at the energy flow only within the building boundaries, from delivered to the final value, the discrict heating has the best thermodynamic compatibility: for heating purpose low temperature and low quality heat was delivered. But, looking at the whole chain of energy transfer, from primary to final value, in this case the problem is located in heat plant. In heat plant the high quality fosil fuel is used for generation low quality thermal energy and it causes high losses of exergy and environmental impact. According to Kallert and Schmidt [30] the usage of district heating system in combination with renewable energy sources gives a great potential for higher sustainability of heating system.

It has been already said that, apart from the state of the analyzed thermodynamic system, the exergy also depends on the state of the environment. The similar exergy analyses shown in literature, was usually done for the constant reference condition for the whole season (project conditions, or average season conditions). In this paper, the analysis was carried out on the monthly basis, for the monthly based reference conditions of environment which are closer to the real situation. Fig. 3 shows a change in the exergy efficiency during the heating season for different energy sources.

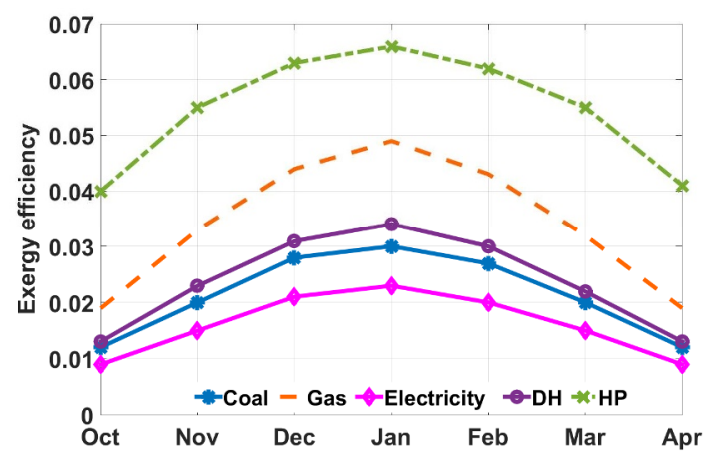

Fig. 3. Monthly values of exergy efficiency for different energy sources 
The difference between the seasonal final exergy value for heating based on monthly conditions and value determined for seasonal average conditions is about $12 \%$. From fig. 3 and fig. 4 , it can be noted that, generally, the exergy efficiency is very low in all cases, which further implies a poor thermodynamic compatibility of energy quality from the supplied side and the energy used for building heating. In case of heat pump the exergy efficiency is the highest (about 6\%), because one part of energy is used from environment.

Exergetic sustainability index $(S I)$ was compared for all considered cases. Due to low exergy efficiencies, the sustainability index also has low values (fig.4). Low values of the sustainability index mean high values of the environmental impact factor, i.e. large losses of exergy throughout the chain of energy transformations.

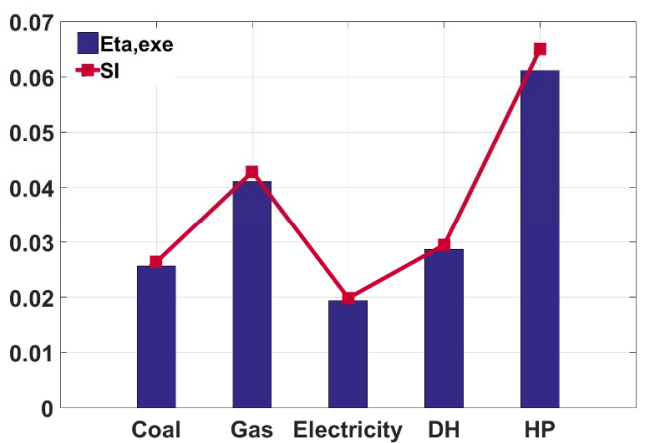

Fig. 4. Seasonal values of exergy efficiency and exergetic sustainability index for different energy sources

Fig. 5 shows a clear link between the $\mathrm{CO}_{2}$ emissions and the environmental impact of the process, expressed through the environmental impact factor. The minimum environmental impact factor (15.37) and maximum exergetic sustainability index $(0.065)$ were found for the case of heat pump utilization. Thermodynamic and sustainability characteristics are the lowest in the case of the of electricity.

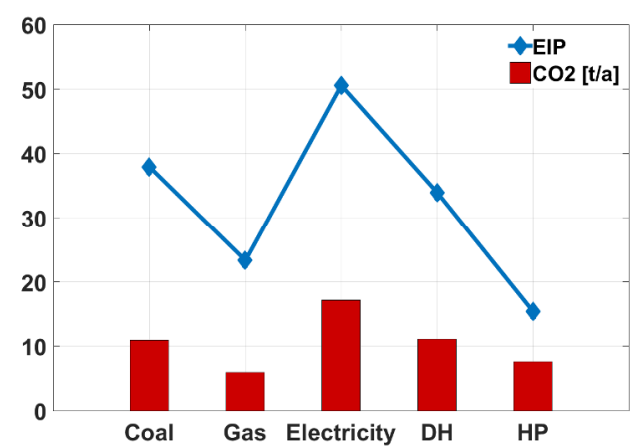

Fig. 5. Environmental impact factor and $\mathrm{CO}_{2}$ emission

In all analyzed cases, the main problem is the process of combustion of fossil fuels, whether in a thermal power plant (in the generation of electricity), or in a heating plant in the case of district heating, or in a boiler for gas or coal in a building (for the generation of low temperature heat). Combustion for direct production of low temperature heat is a highly irreversible process, with a low exergy efficiency and a small exergy sustainability index. In addition, it causes high $\mathrm{CO}_{2}$ emissions and a high environmental impact. Also, it is clearly visible that the usage of electricity for generation of heat is not justified.

\section{Conclusions}

Energy and exergy analyses were conducted for five different heating options of residential building in order to asses sustainability and environmental impact. Energy and exergy flows trough chain of transformation process, then exergy efficiency, exergetic sustainability index and environmental impact factor, are all quantified and illustrated.

The main conclusions that follow from the results of the presented analysis are:

- The exergy method of analysis is suitable for assessing the sustainability and impact on the environment in the case of energy processes;

- The exergy efficiencies of considered heating options are very low. That implies poor thermodynamic compatibility of energy quality from the supplied side and the energy used for building heating and very high losses of exergy;

- The highest exergy efficiency is for the case of heat pump (about 6\%) and the lowest is for the case of electricity utilization (about $2 \%$ );

- The minimum environmental impact factor (15.37) and maximum exergetic sustainability index $(0.065)$ were found for the case of heat pump utilization. The most unfavorable values of these parameters are in the case of the use of electricity;

- Combustion processes should not be used for direct production of low temperature heat, because it is highly irreversible process, with low exergy efficiency, low sustainability and high environmental impact.

This paper was done as a part of the research funded by National Research Projects of Serbian Ministry of Education, Science and Technological Development, Project of Technological Development No. TR33048 and TR33047.

\section{References}

1. European Environmental Agency, Final energy consumption by sector and fuel, (n.d.). https://www.eea.europa.eu/data-andmaps/indicators/final-energy-consumption-bysector-9/assessment-1.

2. H. Torío, A. Angelotti, D. Schmidt, Exergy analysis of renewable energy-based climatisation systems for buildings: A critical view, Energy Build. 41 (2009)

3. A. Angelotti, P. Caputo, The exergy approach for the evaluation of heating and cooling technologies; first results comparing steady state and dynamic simulations, in: Proc. 2nd PALENC 28th AIVC Conf., Crete Island, Greece, (2007) 
4. R. Nishikawa, M. Shukuya, Numerical analysis on the production of cool exergy by making use of heat capacity of building envelopes, in: Proc. 6th Int. IBPSA Conf., Kyoto, Japan, (1999)

5. M. Guadalupe, C. Heard, R. Best, J. Rojas, Exergy analysis of air cooling systems in buildings in hot humid climates, 25 (2005)

6. M. Aa, E. Aursand, E. Magnanelli, J. Pharoah, Performance analysis of heat and energy recovery ventilators using exergy analysis and nonequilibrium thermodynamics, Energy Build. 170 (2018)

7. R. Sangi, P. Jahangiri, A. Thamm, D. Müller, Dynamic exergy analysis - Modelica ${ }^{\circledR}$-based tool development: A case study of CHP district heating in Bottrop, Germany, Therm. Sci. Eng. Prog. 4 (2017)

8. V. Martinaitis, D. Bieksa, V. Miseviciute, Degreedays for the exergy analysis of buildings, Energy Build. 42 (2010)

9. A. Yildiz, A. Güngör, Energy and exergy analyses of space heating in buildings, Appl. Energy. 86 (2009)

10. D. Schmidt, Designing Low " Exergy " Buildings, Int. J. Low Energy Sustain. Build. (2004)

11. A. Abu-Rayash, I. Dincer, Sustainability assessment of energy systems: A novel integrated model, J. Clean. Prod. 212 (2019)

12. E. Açıkkalp, A. Hepbasli, C.T. Yucer, T.H. Karakoc, Advanced life cycle integrated exergoeconomic analysis of building heating systems: An application and proposing new indices, J. Clean. Prod. 195 (2018)

13. C.T. Yucer, A. Hepbasli, Thermodynamic analysis of a building using exergy analysis method, Energy Build. 43 (2011)

14. M.A. Rosen, I. Dincer, M. Kanoglu, Role of exergy in increasing efficiency and sustainability and reducing environmental impact, Energy Policy. 36 (2008)

15. I.S. Dobos, S. Brata, S. Brata, I. Bistran, Calculated and measured energy use before and after thermal renovation for Romanian apartment buildings, REHVA J. 6 (2012)

16. L. Pérez-Lombard, J. Ortiz, C. Pout, A review on buildings energy consumption information, Energy Build. 40 (2008)

17. E.O. Broin, Energy Demands of European Buildings: A Mapping of Available Data, Indicators and Models - MSc Thesis, Chalmers university of technology, (2007).

18. Rulebook on the conditions, content and manner of issuance of certificates of energy performance of buildings, Official Gazette of the Republic of Serbia No.69/2012, Serbia, (2012)

19. Rulebook on the Building Energy efficiency, Official Gazette of the Republic of Serbia No.61/2011, Serbia, (2011)
20. P. Gonçalves, A.R. Gaspar, M.G. Da Silva, Comparative energy and exergy performance of heating options in buildings under different climatic conditions, Energy Build. 61 (2013)

21. M. Gojak, T.S. Bajc, Thermodynamic and economic analysis of different fuels usage on example of residential building, in: Int. Congr. Exhib. Heating, Refrig. Air-conditioning, SMEITS, Belgrade, Serbia, (2018)

22. O.B. Kazanci, M. Shukuya, B.W. Olesen, Effects of floor covering resistance of a radiant floor on system energy and exergy performances, 12th REHVA World Congr. CLIMA. (2016).

23. Y. Cengel, R. Turner, Fundamentals of thermalfluid sciences - Second edition, McGraw-Hill Education, New York, (2005)

24. I. Dincer, M.A. Rosen, Thermodynamic aspects of renewables and sustainable development, Renew. Sustain. Energy Rev. 9 (2005)

25. I. Dincer, M.A. Rosen, Exergy- energy, environment and sustainable development, Elsevier, Burlington, (2007)

26. A. Hepbasli, Towards Developing An Exergy Management System Standard and Its Application to a University Building, CLIMA 2016 - Proc. 12th REHVA World Congr. (2016)

27. H. Aydin, Exergetic sustainability analysis of LM6000 gas turbine power plant with steam cycle, Energy. 57 (2013)

28. M. Adnan, I. Dincer, Development of some exergetic parameters for PEM fuel cells for measuring environmental impact and sustainability, Int. J. Hydrogen Energy. 34 (2009)

29. C.T. Yucer, Exergetic sustainability assessment of a gas turbine jet engine at part loads, Anadolu Univ. J. Sci. Technol. A - Appl. Sci. Eng. 18 (2017)

30. A. Kallert, D. Schmidt, Simulation and exergetic analysis of renewable multi-generation units for a building group, in: CLIMA 2016 - Proc. 12th REHVA World Congr., (2016) 